\title{
Tracheostomy in the Intensive Care Unit: a University Hospital in a Developing Country Study
}

\author{
Mohammad Waheed El-Anwar ${ }^{1} \quad$ Ahmad Abdel-Fattah Nofal $^{1} \quad$ Mohammad A. El Shawadfy $^{1}$ \\ Ahmed Maaty ${ }^{2}$ Alaa Omar Khazbak ${ }^{1}$ \\ ${ }^{1}$ Department of Otorhinolaryngology, Head and Neck Surgery, School \\ of Medicine, Zagazig University, Zagazig, Egypt \\ 2 Department of Anesthesia and Intensive Care Units, School of \\ Medicine, Zagazig University, Zagazig, Egypt \\ Address for correspondence Ahmad Abdel-Fattah Nofal, MD, \\ Department of Otorhinolaryngology, Head and Neck Surgery, School \\ of Medicine, Zagazig University, Zagazig 46166, Egypt \\ (e-mail: nofal_9999@hotmail.com).
}

Int Arch Otorhinolaryngol 2017;21:33-37.

\begin{abstract}
Keywords

- tracheostomy

- endotracheal intubation

- ICU

- mechanical ventilation

Introduction Tracheostomy is the commonest surgical procedure in intensive care units (ICUs). It not only provides stable airway and facilitates pulmonary toilet and ventilator weaning, but also decreases the direct laryngeal injury of endotracheal intubation, and improves patient comfort and daily living activity.

Objective The objective of this study is to assess the incidence, indications, timing, complications (early and late), and the outcome of tracheostomy on patients in the intensive care units (ICU) at a university hospital in a developing country.

Methods This study is an observational prospective study. It was performed at the otolaryngology department and ICU new surgery hospital on 124 ICU admitted patients. We collected patients' demographic records, cause of admission, indications of tracheostomy, mechanical ventilation, and duration of ICU stay. We also gathered patientś tracheostomy records including the incidence, timing, technique, type, early and late complications, and outcome. All tracheostomized patients received follow-up for 12 months.

Results The indication for tracheostomy in ICU patients was mostly prolonged intubation (80.5\%), followed by diaphragmatic paralysis (19.5\%). All tracheostomies were done by the open approach technique. Tracheostomy for prolonged intubation was done within 17 to 26 days after intubation with a mean of $19.4 \pm 2.07$ days. Complications after tracheostomy were $13.9 \%$ tracheal stenosis and $25 \%$ subglottic stenosis.

Conclusion Prolonged endotracheal intubation is the man indication of tracheostomy, performed after two weeks of intubation. Although there were no major early complications, laryngotracheal stenosis is still a challenging sequel for tracheostomy that needs to be investigated to be prevented.
\end{abstract}

received February 19, 2016 accepted April 12, 2016 published online July 26, 2016
DOI http://dx.doi.org/

10.1055/s-0036-1584227. ISSN 1809-9777.
Copyright $\odot 2017$ by Thieme-Revinter

Publicações Ltda, Rio de Janeiro, Brazil
License terms

(요 (1) $\Theta$ 


\section{Introduction}

Tracheostomy is the commonest surgical procedure in intensive care units (ICUs) ${ }^{1,2}$ There are four main general indications for tracheostomy: long term mechanical ventilation, weaning failure, upper airway obstruction, and airway protection. ${ }^{3}$ Tracheostomy in ICU is usually performed for patients with prolonged mechanical ventilation. ${ }^{4}$

Tracheostomy does not only provide stable airway and facilitate pulmonary toilet and ventilator weaning, it also decreases the direct laryngeal injury of endotracheal intubation, and improves patient comfort and daily living activity such as mobility, speech, and eating. ${ }^{5,6}$

Furthermore, early tracheostomy decreases the ventilator time, the incidence of ventilator-associated pneumonia (VAP), length of ICU stay, and overall length of hospital stay. ${ }^{7}$

There are two main tracheostomy techniques: surgical tracheostomy (ST), first described in $1909^{8}$ and performed by surgeons, and percutaneous dilatational tracheotomy (PDT), described in $1985^{9}$ and performed by surgeons, internists, or anesthetists.

So far, the choice of tracheostomy techniques has been a matter of debate, and it is primarily made in accordance with the surgeońs preference rather than by evidence. ${ }^{7,10,11}$

The aim of this study was to assess the incidence, indications, timing, early and late complications, and outcome of tracheostomy in ICU patients of a university hospital in a developing country.

\section{Patients and Methods}

\section{Study Design}

This prospective study took place at the otorhinolaryngology department and ICU of the new surgery hospital, Zagazig University Hospitals, Egypt, from June 2013 to June 2014. All enrolled subjects or their relative signed an informed consent after explanation of the research purpose.

\section{Methods}

All the patients who needed surgical tracheostomy (ST) were transferred to the neighboring operation theater in the same floor within the same hospital (Zagazig new surgery hospital). During the transfer, all patients were assisted by a portable mechanical ventilator. Upon arrival to the operating room, the patient underwent a noninvasive blood pressure monitoring, $5 \mathrm{ECG}$ leads, pulse oximetry, and capnogram for end tidal $\mathrm{CO}_{2}$ monitoring. Anesthesia was induced with propofol $1-2 \mathrm{mg} / \mathrm{kg}$, fentanyl $1-2 \mathrm{mcg} / \mathrm{kg}$, and cis-atracurium $0.1 \mathrm{mg} / \mathrm{kg}$. Then, the lungs were mechanically ventilated to maintain end tidal $\mathrm{CO}_{2}$ tension between 30 to $35 \mathrm{~mm} \mathrm{Hg}$. Anesthesia was maintained with isoflurane $1-1.5 \%$ in $50 \%$ oxygen air. Otolaryngology surgeons performed all the tracheostomies. At the end of the procedure, the surgeon introduced the tracheostomy tube with gradual withdrawal of the endotracheal tube. Then, the patients returned to the ICU, assisted by the portable mechanical ventilator.

In the ICU, the immediate postoperative priorities of care for a patient with a new tracheostomy include ensuring that the tracheostomy tube is secured in place and is patent. Routine care, as well as prompt management of postoperative complication, can be facilitated by ensuring that proper equipment and supplies are quickly available (tracheostomy tube of the same size and 1size smaller, endotracheal tubes of appropriate sizes with intubation equipment, and physiological saline).

No percutaneous dilatational tracheostomy (PDT) was operated in the current study.

We collected data as regarded to demographic patients' record, cause of admission, indications of tracheostomy, mechanical ventilation and duration of ICU stay. Tracheostomy records were also gathered including the incidence of tracheostomy, timing, technique, type, early and late complications, and the patients' outcome had been reported.

All tracheostomized patients received follow-up for 12 months post hospital discharge.

\section{Statistical Analysis}

We performed a statistical analysis using SPSS 14.0 statistical software for Windows (SPSS Inc., Chicago, USA). The significance level was set at $p<0.05$. We used the $t$-test for quantitative data and chi-square test for qualitative data.

\section{Results}

This study includes 124 ICU patients; 108 male (87.1\%) and 16 female (12.9\%) with ages ranging from 12 to 67 years. The mean age was $40.7 \pm 13.4$ years. Tracheostomy was performed for 36 patients (29\%).

All the patients had surgical tracheostomy (ST); 3 (8.3\%) female and 33 (91.7\%) male. The indication for tracheostomy was prolonged intubation in $29(80.5 \%)$ patients and diaphragmatic paralysis in 7 (19.5\%) patients.

All the tracheostomies were surgical tracheostomy (ST) and done in the operative theater with otolaryngology surgeons. So no percutaneous dilatational tracheostomy (PDT) was recorded or tracheostomy done by anesthetists. Horizontal collar incision with mid tracheostomy and removal of part of the tracheal cartilage was used in all cases except in children, with no tracheal flap.

Surgical emphysema, attributed to small tracheostomy tube size, was reported in three cases (8.3\%) and resolved spontaneously. There were no other intraoperative or early post-operative complications and all the patients left the ICU with the tracheostomy tube. Out of the three most common tracheostomy emergencies (hemorrhage, tube dislodgement, and tube obstruction), ${ }^{1}$ we encountered two cases of tubal obstruction in the current study and treated it by changing the tube ( $\boldsymbol{-}$ Table $\mathbf{1})$.

During follow-up after discharge from ICU, 5/36 (13.9\%) patients showed tracheal stenosis; $1(2.8 \%)$ needed surgery and $1(2.8 \%)$ depended on double lumen permanent tracheostomy while the remaining tracheal stenosis was mild and tolerable to the patients. On the other hand, 9/36 (25\%) had subglottic stenosis; all were performed after 21 days of endotracheal intubation, and none of them required surgical interference (-Table $\mathbf{1}$ ). 
Table 1 Indications, complications of tracheostomy and duration between endotracheal intubation and tracheostomy

\begin{tabular}{|l|l|l|}
\hline \multicolumn{2}{|l|}{ Tracheostomy } & Number (percent) \\
\hline Indications & Prolonged intubation & $29(80.5 \%)$ \\
\cline { 2 - 3 } & Diaphragmatic paralysis & $7(19.5 \%)$ \\
\hline Complications & Surgical emphysema & $3(8.3 \%)$ \\
\cline { 2 - 3 } & Tube obstruction & $2(5.6 \%)$ \\
\cline { 2 - 3 } & Tracheal stenosis & $5 / 36(13.9 \%)$ \\
\cline { 2 - 3 } & Subglottic stenosis & $9 / 36(25 \%)$ \\
\hline Duration between endotracheal intubation and tracheostomy & Range & 17 to 26 days \\
\cline { 2 - 3 } & Mean & $19.4 \pm 2.07$ days \\
\hline
\end{tabular}

Tracheostomy for prolonged intubation was done within 17 to 26 days after intubation with a mean of $19.4 \pm 2.07$ days. No tracheostomy was performed within first two weeks of intubation.

ICU stay duration ranged between 2 and 100 days with a mean (SD) of 15.87 (21.4). This duration ranged between 3 to 100 days (mean; $33.5 \pm 30.9$ ) for tracheostomized patients and ranged between 2 to 60 days (mean; $8.6 \pm 10.1$ ) for intubated patients. Thus, there were significantly longer durations of ICU stay in tracheostomized patients ( $\mathrm{t}=3.4253$ and $p=0.0019$ ) (-Table 2 ).

Mechanical ventilation was required in 96/124 (77.4\%) of studied patients and $32 / 36$ of the tracheostomized patients with near significance difference (Chi-square test: 3.817 and $p=0.05)$ (-Table 2).

\section{Discussion}

Patients require long-term mechanical ventilation because of chronic respiratory failure, inability to maintain unassisted respiratory function, or failed weaning from ventilatory support. $^{12}$ We estimated that between $2 \%$ and $11 \%$ of ICU patients who required mechanical ventilation would receive a tracheostomy. $^{13}$

Numerous studies aimed to determine the optimal interval between orotracheal intubation and placement of a trache- ostomy tube, without definitive recommendations due to the varied results in different populations and in patients with distinctive comorbid conditions. ${ }^{12,14}$ The American College of Chest Physicians recommends consideration of tracheostomy for patients who require an endotracheal tube for more than 21 days. ${ }^{15}$ Benefits of establishing a tracheostomy rather than using an endotracheal tube include a decrease in direct laryngeal injury as well as improved comfort and daily activities of living such as mobility, speech, and eating. ${ }^{6}$

The tracheostomy tube may be placed surgically or percutaneously. Percutaneous tracheotomy is generally performed solely on intubated patients and, unlike surgical tracheotomy, it can be performed without direct visualization of the trachea. Bronchoscopy is used to guide and confirm placement of the tracheostomy tube within the trachea. ${ }^{16}$

Surgical placement is done in the operating room or at the bedside, generally under general anesthesia. A common technique is to create a "trap door" (Bj「rk flap), by which a small part of the tracheal cartilage is pulled down and sutured to the skin. ${ }^{16}$ We did not utilize this technique in the current study and conducted all the cases in the operating theater.

Percutaneous dilational tracheotomy (PDT) is the most common technique in most centers, especially in the developed countries. In study of ICU tracheostomy in the United Kingdom, PDT is preferred over the surgical technique; in $43 \%$ of units, PDT is performed in $95 \%$ of cases, in $32.4 \%$ of units it is

Table 2 Differences between tracheostomized and non tracheostomized ICU patients

\begin{tabular}{|l|l|l|l|}
\hline & Tracheostomized ICU patients & Other ICU patients & $P$ value \\
\hline Cases & & & $\begin{array}{l}0.33 \mathrm{NS} \\
\left(\mathrm{x}^{2}=0.943\right)\end{array}$ \\
\hline Total & 36 & 88 & $75(88.2 \%)$ \\
\hline Male & $33(91.7 \%)$ & $13(14.8 \%)$ & \\
\hline Female & $3(8.3 \%)$ & $64 / 88(72.7 \%)$ & $\begin{array}{l}0.05 \text { near S } \\
\left(X^{2}=3.817\right)\end{array}$ \\
\hline Mechanical ventilation & $32 / 36(88.9 \%)$ & $\begin{array}{l}\text { All ICU patients, } \\
15.87(21.4) \\
\text { For intubated ICU patients } \\
8.6 \pm 10.1\end{array}$ & $\begin{array}{l}0.0004 \mathrm{~S} \\
(\mathrm{t}=3.6365) \\
0.0019 \mathrm{~S} \\
(\mathrm{t}=3.4253)\end{array}$ \\
\hline Mean ICU stay & $33.5 \pm 30.9$ & & \\
& & &
\end{tabular}

Abbreviations: ICU, Intensive Care Unit; S, significant; NS, non-significant. 
done in $75-95 \%$ of cases, in $16.6 \%$ of units it is done in 50 to $75 \%$ of cases, while in only $8 \%$ of units, ST is preferred with PDT accounting for less than $50 \%$ of cases. ${ }^{17}$ In many studies about tracheostomy in ICU in many of European countries, PDT was usually the preferred technique; in Italy, it accounted for $89 \%$ of cases, ${ }^{18}$ in Germany, $86 \%$ of cases, ${ }^{11}$ in Spain, $72 \%$ of cases, ${ }^{19}$ and in the Netherlands, $62 \%$ of cases. ${ }^{20}$

Surgical tracheotomy (ST) is the only technique used in our center; this is mainly due to the cost effectiveness, which is in the favor of ST because of the cost of the PDT insertion set as well as the otolaryngology surgeońs easy 24-hour accessibility to the hospital. Furthermore, insufficient expertise in performing PDT can be added to the cause of preference of ST.

This agrees with the result of other studies ${ }^{21,22}$ about tracheostomy in ICU in Nigeria's teaching hospital in which all the tracheostomies were surgical tracheostomy. In one of the international survey about tracheostomy in ICU; they found that ST was the most popular tracheotomy technique outside Europe, and was mainly performed by ENT specialists. ${ }^{23}$ Even in some developed countries, such as France, the ST technique is still preferred over PDT. ${ }^{24}$

The importance of this study is while it was done in the ICU of a surgery hospital, so it was dealing mostly with surgical cases, which differ from other studies, which may include non-surgical cases, and even data of the met analysis studies involve nonsurgical ICUs. At the same time, since study took place in a developing country, the cost effectiveness favors ST over PDT, because of ST́s low-cost versus the cost of the single-use PDT tracheostomy set, as well as the availability of the surgical team.

In the study by Kluge et $\mathrm{al}^{11}{ }^{11} 86.1 \%$ of ICUs routinely perform PDT and only $13.9 \%$ of ICUs perform ST; however, in answering a question of "which method is according to your opinion is safer," $50 \%$ answered there was no difference between the two methods, 27\% answered PTD, and 19\% answered ST.

Some review studies prefer PTD over ST because there is no need for the operating room (OR), it is less expensive, the reduced time between decision and performance of tracheostomy, and lower mortality rate. ${ }^{3}$ In our study, however, the ICU is located in the same floor neighbor as the OR, and otolaryngology doctors are freely available $24 / 7$ in the university hospital. This overrides the problems from transferring the patients from the ICU to the OR, as well as reduces the time between the decision and the performance of the tracheostomy. In fact, the ST turns out to be cheaper than PDT (no need for the costly disposable PDT set). As for mortality rate, there are many studies that found no difference between ST and PDT in this regard. ${ }^{7,10,11}$ Because of the significant effect of tracheostomy on the patients life, it must be included in any learning process undergone by the otolaryngologist.

The results of current study showed that prolonged endotracheal intubation is the main indication of tracheostomy, and surgical open tracheostomy remains the most used technique in our institutional hospitals. We found no significant early complications, but still laryngeotracheal stenosis is an important reported late complication that needs to be studied to manage factors related to occurrence of such a complication.

Although the incidence of laryngotracheal stenosis in this study was $14 / 36$ cases (39\%), only two cases (5.5\%) were significantly affected and needed intervention, either with surgery or permanent tracheostomy. In our concept, we did not attribute this to the tracheostomy technique per se, but mostly due to the long intubation period preceding it (more than 21 days), particularly since tracheostomy in ICU is elective.

International and national surveys report as the prevailing timing of tracheostomy between 7 to15 days. ${ }^{11,17-20,23}$ Some studies consider early tracheostomy to happen within 4 days of intubation and late tracheostomy after 10 days. ${ }^{25}$ Thus, we hope to introduce the concept of earlier tracheostomy to a greater extent that the current protocol in our center, to avoid most of tracheostomy complications.

\section{Conclusion}

Prolonged endotracheal intubation is the main indication for patients that have undergone tracheostomy performed after two weeks of intubation, in all cases. Although it does not present major early complications, laryngeotracheal stenosis is still an unresolved sequel for tracheostomy that needs to be further investigated so it can be prevented.

\section{References}

1 Garner JM, Shoemaker-Moyle M, Franzese CB. Adult outpatient tracheostomy care: practices and perspectives. Otolaryngol Head Neck Surg 2007;136(2):301-306

2 Freeman $\mathrm{BD}$, Isabella K, Cobb JP, et al. A prospective, randomized study comparing percutaneous with surgical tracheostomy in critically ill patients. Crit Care Med 2001;29(5):926-930

3 De Leyn P, Bedert L, Delcroix M, et al; Belgian Association of Pneumology and Belgian Association of Cardiothoracic Surgery. Tracheotomy: clinical review and guidelines. Eur J Cardiothorac Surg 2007;32(3):412-421

4 MacIntyre NR, Epstein SK, Carson S, Scheinhorn D, Christopher K, Muldoon S; National Association for Medical Direction of Respiratory Care. Management of patients requiring prolonged mechanical ventilation: report of a NAMDRC consensus conference. Chest 2005;128(6):3937-3954

5 Koh WY, Lew TW, Chin NM, Wong MF. Tracheostomy in a neurointensive care setting: indications and timing. Anaesth Intensive Care 1997;25(4):365-368

6 Bittner EA, Schmidt UH. The ventilator liberation process: update on technique, timing, and termination of tracheostomy. Respir Care 2012;57(10):1626-1634

7 Möller MG, Slaikeu JD, Bonelli P, Davis AT, Hoogeboom JE, Bonnell BW. Early tracheostomy versus late tracheostomy in the surgical intensive care unit. Am J Surg 2005;189(3):293-296

8 Jackson C. Tracheostomy. Laryngoscope 1909;19(4):285-290

9 Ciaglia P, Firsching R, Syniec C. Elective percutaneous dilatational tracheostomy. A new simple bedside procedure; preliminary report. Chest 1985;87(6):715-719

10 Klotz R, Klaiber U, Grummich K, et al. Percutaneous versus surgical strategy for tracheostomy: protocol for a systematic review and meta-analysis of perioperative and postoperative complications. Syst Rev 2015;4(1):105

11 Kluge S, Baumann HJ, Maier C, et al. Tracheostomy in the intensive care unit: a nationwide survey. Anesth Analg 2008;107(5): 1639-1643

12 Masoudifar M, Aghadavoudi O, Nasrollahi L. Correlation between timing of tracheostomy and duration of mechanical ventilation in patients with potentially normal lungs admitted to intensive care unit. Adv Biomed Res 2012;1:25 
13 Diaz-Prieto A, Mateu A, Gorriz M, et al. A randomized clinical trial for the timing of tracheotomy in critically ill patients: factors precluding inclusion in a single center study. Crit Care 2014;18; (5):585

14 Brook AD, Sherman G, Malen J, Kollef MH. Early versus late tracheostomy in patients who require prolonged mechanical ventilation. Am J Crit Care 2000;9(5):352-359

15 Plummer AL, Gracey DR. Consensus conference on artificial airways in patients receiving mechanical ventilation. Chest 1989; 96(1):178-180

16 Bove MJ, Afifi MS. Tracheotomy procedure. In: Morris LL, Afifi MS, eds. Tracheostomies: The Complete Guide. New York, NY: Springer Publishing Co LLC; 2010:17-40

17 Veenith T, Ganeshamoorthy S, Standley T, Carter J, Young P. Intensive care unit tracheostomy: a snapshot of UK practice. Int Arch Med 2008;1(1):21

18 Vargas M, Servillo G, Arditi E, et al. Tracheostomy in Intensive Care Unit: a national survey in Italy. Minerva Anestesiol 2013;79; (2):156-164

19 Añón JM, Escuela MP, Gómez V, García de Lorenzo A, Montejo JC, López J. Use of percutaneous tracheostomy in intensive care units in Spain. Results of a national survey. Intensive Care Med 2004; 30(6):1212-1215

20 Fikkers BG, Fransen GA, van der Hoeven JG, Briedé IS, van den Hoogen FJ. Tracheostomy for long-term ventilated patients: a postal survey of ICU practice in The Netherlands. Intensive Care Med 2003;29(8):1390-1393

21 Okafor U, Nwosu J. Tracheostomy in the Intensive Care Unit: A Developing Country Experience. Internet Journal of Otorhinolaryngology 2008;9(2):17

22 Amusa YB, Akinpelu VO, Fadiora SO, Agbakwuru EA. Tracheostomy in surgical practice: experience in a Nigerian tertiary hospital. West Afr J Med 2004;23(1):32-34

23 Vargas M, Sutherasan Y, Antonelli M, et al. Tracheostomy procedures in the intensive care unit: an international survey. Crit Care 2015;19(1):291

24 Blot F, Melot C; Commission d'Epidémiologie et de Recherche Clinique. Indications, timing, and techniques of tracheostomy in 152 French ICUs. Chest 2005;127(4):1347-1352

25 Terragni PP, Antonelli M, Fumagalli R, et al. Early vs late tracheotomy for prevention of pneumonia in mechanically ventilated adult ICU patients: a randomized controlled trial. JAMA 2010;303(15):1483-1489 